\title{
A educação ambiental na educação infantil - reflexão para uma prática significativa
}

\author{
Environmental education in early childhood education - reflection on meaningful practice \\ La educación ambiental en la educación infantil - reflexión para una práctica significativa \\ Cintia Andrezza dos Santos Diamantino ${ }^{1 *}$, Katia Gonçalves Castor ${ }^{1}$.
}

\begin{abstract}
RESUMO
Objetivo: Apresentar reflexões sobre a importância da educação ambiental na educação infantil, visto que a agressão ao meio ambiente aumenta a cada dia causando grandes danos à natureza e são decorrentes, principalmente da ação inadequada do homem, que vem contribuindo para a degradação do meio ambiente com o consumismo desenfreado, o egoísmo, a ganância e a falta de consciência. Revisão bibliográfica: Percebe-se que há vasta literatura abordando assuntos relacionados à educação ambiental e muitas concordam ser de grande relevância à inserção das temáticas ambientais para um pensamento reflexivo e crítico, pensando nas mudanças de atitudes, desde a educação infantil, para um reflexo significativo e mudanças tanto na cultura das crianças, como dos pais, pois a criança ensina em casa o que aprende na escola. Considerações finais: Com esta pesquisa foi possível concluir que urge uma mudança de comportamentos e que é possível uma mudança de hábitos através de um trabalho contextualizado e significativo, portanto, cabe à escola a busca pelos melhores métodos de ensino a fim de incentivar os alunos a um pensamento crítico, reflexivo e sensível quanto às questões ambientais.
\end{abstract}

Palavras-chave: Educação ambiental, Educação infantil, Práticas educacionais.

\section{ABSTRACT}

Objective: To present reflections on the importance of environmental education in early childhood education, since the aggression to the environment increases every day causing great damage to nature and are due mainly to the inadequate action of man, which has contributed to the degradation of the environment with rampant consumerism, selfishness, greed and lack of awareness. Bibliographic review: It is noticed that there is a vast literature addressing issues related to environmental education and many agree that it is of great relevance to the insertion of environmental themes for reflective and critical thinking, thinking about changes in attitudes, from early childhood education, to a significant reflection and changes in the culture of both children and parents, as the child teaches at home what he learns at school. Final considerations: With this research it was possible to conclude that a change in behavior is urgent and that a change in habits is possible through contextualized and meaningful work, therefore, it is up to the school to search for the best teaching methods in order to encourage students to critical, reflective and sensitive thinking about environmental issues.

Key words: Environmental education, Children's education, Educational practices.

\section{RESUMEN}

Objetivo: Presentar reflexiones sobre la importancia de la educación ambiental en la educación infantil, ya que la agresión al medio ambiente aumenta día a día provocando grandes daños a la naturaleza y se deben principalmente a la actuación inadecuada del hombre, que ha contribuido a la degradación del medio ambiente. con consumismo desenfrenado, egoísmo, codicia y falta de conciencia. Revisión bibliográfica: Se advierte que existe una vasta literatura que aborda temas relacionados con la educación ambiental y muchos coinciden en que es de gran relevancia para la inserción de temas ambientales para el pensamiento reflexivo y crítico, pensando en cambios de actitudes, desde la educación infantil, a una reflexión y cambios significativos en la cultura tanto de los niños como de los padres, ya que el niño enseña en casa lo que

${ }^{1}$ Faculdade Vale do Cricaré (FVC), São Mateus - ES. *E-mail: cintiapedagogasm@gmail.com 
aprende en la escuela. Consideraciones finales: Con esta investigación se pudo concluir que un cambio de comportamiento es urgente y que un cambio de hábitos es posible a través de un trabajo contextualizado y significativo, por lo que le corresponde a la escuela buscar los mejores métodos de enseñanza para animar a los estudiantes a un pensamiento crítico, reflexivo y sensible sobre los problemas ambientales.

Palabras clave: Educación ambiental, Educación infantil, Prácticas educativas.

\section{INTRODUÇÃO}

De acordo com Guisso LF e Baiôco VRM (2016), a educação acontece durante toda vida do individuo desenvolvendo-se de forma contínua e dinâmica a fim de que sejam estimuladas competências que levem à reflexão e atitudes com o intuito de sensibilizar as pessoas ultrapassando a visão antropocêntrica - em que o homem é visto como centro de tudo - onde a importância maior era dada ao homem e seus interesses e a natureza era vista como fonte inesgotável de recursos a serem extraídos.

Assim, a Educação Ambiental é vista como agente difusor dos conhecimentos sobre o meio ambiente e gerador de mudança dos hábitos compatíveis com a preservação, voltados principalmente para a educação popular como forma de sensibilização tanto dos alunos como dos pais sobre a importância de cuidar do meio ambiente (CARVALHO ICM, 1992). De acordo com a Política Nacional de Educação Ambiental, Lei ํo 9.795/1999, artigo 1ㅇ:

"Entendem-se por educação ambiental os processos por meio dos quais o individuo e a coletividade constroem valores sociais, conhecimentos, habilidades, atitudes e competências voltadas para a conservação do meio ambiente, bem de uso comum do povo, essencial à sadia qualidade de vida e sua sustentabilidade".

Nesse sentido o papel do educador é de suma importância, pois é este o agente capaz de proporcionar a seus educandos mudanças de comportamento, práticas voltadas para a preservação e reutilização, além de estratégias e didáticas interdisciplinares que promovam um desenvolvimento integral e em equipe, criando métodos para o exercício prático da cidadania, sintetizando as dimensões do processo socioambiental. (GUISSO LF e BAIÔCO VRM, 2016).

Para tanto, a Educação Ambiental iniciar-se desde a Educação Infantil é importante e urgente, pois é uma fase onde as crianças desenvolvem a capacidade de agir, observar e explorar tudo o que encontram ao seu redor, tornando-se participantes ativas frente às situações socioambientais cotidianas. Segundo Tristão M (2002), "deve-se ampliar a função da escola, onde ainda existe a cultura, na maior parte do tempo, de simples transmissão de conhecimento e passe a tornar-se um estabelecimento de ensino como foco em uma comunicação crítica, criadora de um sistema imaginativo e transformador da cultura e do ser humano".

Face ao exposto, o presente estudo tem como objetivo apresentar reflexões sobre a importância da educação ambiental na educação infantil, visto que a agressão ao meio ambiente aumenta a cada dia causando grandes danos à natureza e são decorrentes, principalmente da ação inadequada do homem, que vem contribuindo para a degradação do meio ambiente com o consumismo desenfreado, o egoísmo, a ganância e a falta de consciência.

\section{REVISÃO BIBLIOGRÁFICA}

\section{O contexto da educação ambiental}

Ao longo dos séculos, a necessidade de consumir para sobreviver cedeu lugar a novas e complexas necessidades de cunho social e emocional para responder ao desejo do indivíduo de mostrar-se aos outros e chancelar seu pertencimento a um grupo ou classe social. O consumo envolve o indivíduo de tal forma que alimenta e incentiva a dinâmica da sociedade capitalista contemporânea com a qual sua prosperidade depende intrinsecamente do ato de consumir e de sua necessidade de pertencimento social. Deste modo, o consumo deixou de ser uma ocupação dos seres humanos e passou a ser um atributo da sociedade na forma de um consumismo que associa a felicidade a um volume e a uma intensidade de desejos sempre crescentes (BAUMAN Z, 2007). Portanto, é perceptível que o capitalismo está muito presente no processo de degradação 
da natureza e uma das tarefas da escola é formar cidadãos críticos que não aceitem a repressão e tenham ideias próprias, sensibilizando-se sobre o quanto o planeta precisa de pessoas que não o destrua.

Segundo Sousa BS e Souza EA (2014), as escolas têm um papel imprescindível no ensino/aprendizagem da educação ambiental tanto na Educação Infantil (início da vida escolar das crianças) como em todas as outras etapas escolares. Desde os primeiros anos escolares são apresentados à criança os direitos e deveres de todo cidadão, mas o que muitas vezes é deixado de lado é como fazê-las cumprir. E sem dúvida, a preservação do meio ambiente é um dever de cada um, pois preservá-lo é preservar o futuro, e quanto mais cedo o tema for abordado com as crianças, maiores as chances de despertar a consciência pela preservação. Por isso, a educação para uma vida sustentável deve começar já na creche já com os bebês e o educador deve relacionar o assunto à realidade para que haja sentido entre o que está sendo explorado com o aluno e sua realidade e assim, ser colocado em prática a fim de uma aprendizagem significativa e reflexiva.

Assim, Guimarães MA (2004), defende que a maior parte dos professores está sensibilizada contra a degradação da natureza, e se mobiliza, com empenho sincero, para enfrentar essa questão, mas as práticas resultantes geralmente são pouco eficazes para mudar, de forma significativa, a realidade mais imediata com a qual estão lidando e, reciprocamente, com uma realidade mais ampla.

Já Penteado HD (1997), afirma que diferente de ler sobre o meu meio ambiente e ficar informado sobre ele, o que deve acontecer concretamente é observar diretamente o ambiente em que vivemos, entrar em contato direto com os diferentes grupos sociais que o compõem, observar como as relações sociais permeiam esse meio e o exploram, coletar junto às pessoas informações sobre as relações que mantêm com o meio ambiente em que vivem, enfim, apreender como a sociedade lida com ele e assim entender como o meio ambiente e o que tem ocorrido com ele afeta diretamente a vida de todos.

Desse modo, diversos modelos de educação ambiental conhecidos como convencionais buscam educar ambientalmente para a mudança de conhecimentos, valores, hábitos, comportamentos, atitudes etc. Porém esses modelos acabam não assumindo a natureza estrutural da crise ambiental, ou seja, não entendem a problemática ambiental como um desajuste do funcionamento das sociedades contemporâneas e acabam confinados pelos limites que impõem a mesma lógica do sistema no qual estão inseridos (CARTEA PAM, 2006). Convém ressaltar ainda que, na Educação Infantil, as crianças estão em constante processo de desenvolvimento, e é nesta fase, que os educadores podem e devem intervir de maneira eficaz permitindo que as crianças passem a ser sujeitos mais reflexivos e críticos, com relação aos temas ambientais.

É desafiador pensar em conscientizar crianças tão pequenas para tratar tais temas visto que não existe, até então, um modelo didático explícito que guie a intervenção das professoras e que tenha como objetivo dar coerência à prática e estimular uma reflexão crítica e profunda sobre a racionalidade dominante, mas devemos perceber que é possível trabalhar a temática nas ocorrências da rotina diária da escola, em momentos de pátio e até mesmo quando fazemos inclusões de materiais, seguido de recreações e ludicidade. Esse pode ser um primeiro passo considerável nessa faixa etária da primeira infância (SOUSA BS E SOUZA EA, 2014).

A transversalidade é o caminho, dentre todos os autores lidos. Não há como pensar educação, muito menos em educação ambiental, sem que seja transversal, multidisciplinar e libertadora. Não virá dos que promovem os danos ambientais a mudança. Não virão dos poluidores as soluções ambientais e, nem se há de esperar que deste grupo surjam propostas plausíveis de reforma educacional, pois, a educação conservadora é um dos pilares do sistema cruel que mantém o indivíduo/cidadão à margem do processo civilizatório (RODRIGUES LHPF, 2015).

Tozoni-Reis MFC (2006), faz uma ponte entre a educação ambiental e a sustentabilidade, apoiadas por uma metodologia transdisciplinar, trazendo a total interação entre estas áreas. Ela firma que para que haja eficácia neste processo de aprendizado e construção de cidadania, envolvendo uma nova concepção de educação para atingir uma consciência socioambiental de sustentabilidade, é imprescindível que seja permanente. Educar para consciência ambiental, principalmente se voltada à sustentabilidade é um processo de conscientização, de educação política e, incisivamente determina a autora, despida de neutralidade. A autora vai além, quando afirma que da Educação clássica não poderá emergir uma Educação Ambiental 
eficaz. Terá que ser nova, com outras bases e comprometimento. Com isso, fica clara a imprescindibilidade em construir um novo pensamento político resultante da participação dos sujeitos envolvidos de forma direta, o que exige responsabilidades individuais e coletivas. A sustentabilidade passou então a ser entendida como peça chave para a educação ambiental crítica, realmente transformadora e emancipatória.

Além disso, se percebe também, a necessidade de um maior investimento na formação de educadores ambientais através da inclusão da educação ambiental como uma área de formação em todos os cursos de graduação e cursos profissionalizantes. E, em conjunto com este trabalho, promover a integração e a troca de experiência dos que já atuam nesta área com o objetivo de reduzir as disputas que existem entre as diversas formações destes profissionais e estimular o intercâmbio de ideias entre estes setores e, assim, tentar superar as visões parciais dentro da educação ambiental. Assim, se confirma no plano de ação da Coordenação de Educação ambiental do MEC, de 1996, ainda prevê que se é importante para as instituições de ensino, não somente a abordagem destes conteúdos, mas como a capacitação de docentes para que essas ações sejam consistentes e sistemáticas e ainda ressalta que essa medida deve acontecer em todo 0 país garantindo incorporação em todas as modalidades de ensino. (CAMPOS MAT e CARVALHO AM, 2015).

\section{A cultura da sustentabilidade e o desenvolvimento sustentável}

Atualmente, a problemática ecológica como o esgotamento das reservas de petróleo, a escassez de água potável, a explosão demográfica de diversas nações do mundo e a busca para conquistar um elevado padrão de desenvolvimento econômico têm exigido muito do meio ambiente. Assim, são necessárias mudanças nas atitudes dos indivíduos e das empresas na busca por alternativas desses e de outros problemas ambientais e sociais que afligem a sociedade. Nessa conquista, a educação ambiental é fator determinante. Através da conscientização, agregando conhecimento e informações, valorizando as estratégias e decisões que beneficiam a natureza, respeitando a sua preservação e conservação em detrimento de sua devastação, é possível construir uma nova sociedade. Assim, é possível observar um consenso quanto a influência da questão populacional sobre a degradação ambiental e decorrentemente sobre a utilização dos recursos naturais, bem como sua capacidade de regeneração (AUGUSTIN S, et al., 2014).

Para tanto, Guisso LF e Baiôco VRM (2016), nos convida a refletir que desenvolver a cultura da sustentabilidade representa utilizar os recursos escassos disponíveis, de forma que não comprometa o futuro das próximas gerações e para consolidar o Desenvolvimento Sustentável, é necessária uma educação ambiental prática, voltada à formação da personalidade, incentivando a consciência ambiental, apreciando e valorizando os recursos naturais.

Já Jorge MJF (2015), afirma que a falta de conhecimento do ser humano em relação à sustentabilidade e ao que isto implica, poderá trazer conseqüências catastróficas. Nos dias de hoje é preciso que cada indivíduo tenha a consciência de que é necessário se preocupar e cuidar do meio ambiente no qual se vive. E para isto, é preciso estar atento a cada atitude tanto individual como coletiva e repensar a forma como se vive dentro deste ambiente. A continuação e sobrevivência da raça humana estão totalmente dependentes da conservação dos recursos naturais de nossas matas, florestas, rios, lagos e oceanos.

Dentro desse contexto, há necessidade de comprometimento por parte dos governantes a fim de firmar políticas públicas voltadas ao Desenvolvimento Sustentável com investimentos constantes e necessários na educação ambiental, despertando na sociedade a preocupação com a preservação do meio ambiente (GUISSO LF e BAIÔCO VRM, 2016). Consequentemente gerar uma mudança de paradigma ao nível legislativo, doutrinal, jurisprudencial, cultural, político, econômico, social e individual, que sempre se consubstanciará numa tomada de consciência pessoal, local e governamental com a consequente adoção de exemplos úteis a seguir, de modo a reforçar o desenvolvimento sustentável.

\section{Educação ambiental na educação infantil, um diálogo possível}

Entende-se que a educação Ambiental é um processo que deve ser estabelecido em longo prazo, pois para alcançá-la o sujeito necessita evoluir intelectualmente para refletir num contexto mais amplo, tal como seu papel de agente transformador de práticas em sua vida diária e profissional que impactam negativamente sobre o meio ambiente (ROOS A e BECKER ELS, 2012). Concorda-se que o Ensino Superior não é o melhor 
momento para a inserção de uma abordagem educacional em educação ambiental, e que a educação infantil certamente é o melhor caminho, por ser a fase inicial da educação, por ser o momento em que a criança está na fase de descobertas do mundo que a cerca.

Convém ressaltar que, na Educação Infantil, as crianças estão em constante processo de desenvolvimento, e é nesta fase, que os educadores podem e devem intervir de maneira eficaz permitindo que as crianças passem a ser sujeitos mais reflexivos e críticos, com relação aos temas ambientais e entre outras conquistas, as crianças estão geneticamente capacitadas, na primeira infância, para aprender a caminhar e a falar. O domínio dessas habilidades permite que ela apreenda e transforme o universo físico e simbólico que a cerca.

No entanto, a infância é uma fase muito importante para o ser humano onde a criança traz muitas dúvidas, porém sua capacidade de assimilação e aprendizagem é muito grande para a compreensão do mundo e as transformações que ocorrerão ao longo da sua vida. Ainda, na infância está implícita a manipulação do mundo externo pela criança onde há separação entre o "conhecedor" e o "conhecido". Por isso, é inquestionável a importância de se desenvolver conceitos de Educação Ambiental com atividades lúdicas na Educação Infantil, uma vez que a sociedade brasileira ainda não resolveu os problemas ambientais mais elementares, tais como separação adequada do lixo, poluição de solos e água, desmatamentos, dentre outros (TRISTÃO MP, 2005).

O papel da escola é construir sujeitos com uma postura crítica com conteúdos relacionados à realidade para o desenvolvimento da conscientização, com suas preocupações mundiais e locais. Portanto, o tema ambiental é uma questão que deveria estar sempre presente no discurso educacional para que os alunos possam realmente pensar sobre assuntos presentes em sua realidade e refletir sobre as soluções dos problemas que interferem no bem-estar de sua comunidade.

Nota-se que os alunos precisam desde o princípio da sua vida escolar, estar em contato com conceitos que fazem parte da discussão ambiental para que possam compreender a complexidade de certos termos e desta forma entender a relação política das questões ambientais.

De acordo com Dewey J (1971), A promoção da Educação Ambiental nas escolas tem como objetivo conscientizar as crianças, mas, além disso, também é preciso que os educadores criem situações de aprendizagem que envolva a comunidade escolar no sentido de pensarem propostas de intervenção na realidade, pois sem um trabalho coletivo e bem direcionado, as ações poderiam se perder ao longo do processo ensino aprendizagem. No caderno que apresenta o programa Parâmetros em Ação Meio Ambiente na Escola do Ministério da Educação é afirmada a importância da escola, quando expõe que:

A escola desempenha um papel fundamental na garantia de um futuro sustentável para todos, na medida em que tem o poder de, ao educar os alunos, formar os cidadãos. Por isso, na história da Educação Ambiental, a escola sempre foi considerada uma instituição privilegiada para a formação de cidadãos sensíveis e responsáveis em relação à questão ambiental (BRASIL, 2001, p. 19).

E no caso da Educação Infantil, a melhor maneira de tratar tais conceitos é através da interação entre os sujeitos e seu meio, pois quanto mais contato a criança tiver com a natureza, melhor será sua compreensão e desejo em preservá-la, não adianta o professor dizer para o aluno que nas matas existem diversos animais silvestres que estão sendo extintos por causa dos desmatamentos, queimadas, crescimento das cidades e a criança não ver, não vivenciar. É comum crianças que moram nas cidades e passam a maior parte do tempo em apartamentos e nunca tocaram em um animalzinho, nem de estimação, nunca tomaram banho no rio, ou participaram do plantio de alguma planta. De acordo Referencial Curricular Nacional para a Educação Infantil (RCNEI) a criança:

"se constitui em um conjunto de fenômenos naturais e sociais indissociáveis diante do qual elas se mostram curiosas e investigativas. Desde muito pequenas, pela interação com o meio natural e social no qual vivem, as crianças aprendem sobre o mundo, fazendo perguntas e procurando respostas às suas indagações e questões. Como integrantes de grupos socioculturais singulares, vivenciam experiências e interagem num contexto de conceitos, valores, ideias, objetos e representações sobre 
os mais diversos temas a que têm acesso na vida cotidiana, construindo um conjunto de conhecimentos sobre o mundo que as cerca". (Referencial Curricular Nacional para a Educação Infantil, BRASIL, 1998, v.3, p.163).

Por isso, é importante o educador promover momentos em que a criança possa vivenciar algumas dessas atitudes que talvez a criança nunca venha a viver. Algumas ações como horta na escola, passeios em trilhas ecológicas, visitação em museus ou projetos de conservação ambiental são alguns caminhos. Melhor do que folhear livros com desenhos e figuras de paisagens e animais, esse tipo de metodologia leva a criança a vivenciar efetivamente práticas com o meio ambiente, de forma lúdica e prazerosa conforme sugestiona (TRISTÃO MP, 2005).

No caso de horta como uma metodologia ampla, dinâmica e que perpassa muito além o ato do cultivo, em si, Marvila LC (2019), defende que com a construção de uma horta escolar é possível estimular os alunos a adquirirem hábitos saudáveis, pois ao cultivar, cuidar e colher será possível ampliar seu conhecimento de diferentes tipos de alimento e ao ver o crescimento das hortaliças eles têm a oportunidade de provar o fruto de seu trabalho e com isso aceitação desses alimentos já que muitas crianças e adolescente os rejeita.

Assim, é preciso que professores e professoras se fortaleçam como aprendizes da sustentabilidade. E isto transcende de longe a réplica de livros e teorias. Leva a pensar em escolas sustentáveis desde sua estrutura até o sistema escolar, envolvendo todos os atores sociais dentro da escola e em seu entorno, o que inclui a socialização de ideias, de espaços, de material didático contextualizado e de convivência sociocultural, função relevante do ambiente escolar, que não se restringe aos muros da escola, mas ao contrário, perpassa por todo e qualquer lugar por onde a criança interaja.

\section{CONSIDERAÇÕES FINAIS}

A Educação Ambiental é imprescindível e necessária dentro do ambiente escolar e desde a educação infantil, pode mudar hábitos, transformando a situação do planeta Terra além de proporcionar uma melhor qualidade de vida. Assim é possível perceber que já existe vasta literatura dialogando com o tema e possíveis soluções para a problemática ambiental. Assim, é necessário ser tratado o assunto nas escolas de forma a direcionar o aluno para um pensamento crítico e sensível, consequentemente atinge a família e a sociedade como um todo. Portanto, espera-se que esse trabalho desperte interesse tanto em educadores como na sociedade em geral, afirmando que é possível uma mudança de comportamento partindo da abordagem crítica, qualitativa e com foco na sensibilização.

\section{REFERÊNCIAS}

1. AUGUSTIN S, et al. A influência da densidade populacional no desenvolvimento sustentável (2014); EDUCS - Editora da Universidade de Caxias do Sul - RS: 89-116.

2. BAUMAN Z. Vida para consumo: a transformação das pessoas em mercadoria. Trad. Carlos A. Medeiros. Rio de Janeiro: Jorge Zahar, 2007.

3. BRASIL. Lei n. 9795 - 27 de abril de 1999. Dispõe sobre a Educação Ambiental. Política Nacional de Educação Ambiental. Brasília, 1999.

4. BRASIL. Lei n. 9795 - 27 de abril de 1999. Dispõe sobre a Educação Ambiental. Política Nacional de Educação Ambiental. Brasília, 1999.

5. BRASIL, MEC. Secretaria de Educação Fundamental. Parâmetros Curriculares Nacionais: terceiro e quarto ciclos do ensino fundamental. Língua Portuguesa. Secretaria de Ensino Fundamental. Brasília: MEC/SEF, 2001.

6. BRASIL. Ministério da Educação e do Desporto. Referencial Curricular Nacional para a Educação Infantil. Brasília: MEC/SEF, 1998.

7. CAMPOS MAT, CARVALHO AM. Desafios emergentes na ação educativo-ambiental: uma experiência em centros de educação infantil de Curitiba - PR. Holos, 2015; 31(5).

8. CARTEA PAM. Las barreras sociopolíticas para la práctica de uma educacíon ambiental radical em lãs sociedades avanzadas: lo que podemos aprender de labasura. In: Anais do V Congresso Iberoamericano de Educação Ambiental, 5e. ed., Joinville, 2006.

9. CARVALHO ICM. Educação, meio ambiente e ação política. Meio ambiente e democracia. Rio de Janeiro: Ibase, 1992; 32-4p.

10. DEWEY J. Experiência e educação. São Paulo: Nacional, 1971.

11. GUIMARÃES M. Educação ambiental crítica. In: LAYRARGUES, Philippe (Org.). Identidades da educação ambiental brasileira. Brasília: Ministério do Meio Ambiente/Diretoria de Educação Ambiental, 2004. 
12. GUIMARÃES MA. Formação de Educadores Ambientais. Campinas: Papirus, 2004.

13. GUISSO LF, BAIÔCO VRM. A educação ambiental e o papel do educador na cultura da sustentabilidade. Revista ea, 2016: 58

14. JORGE MJF. A cultura da Sustentabilidade Social, um instrumento de Humanização, Coimbra, Janeiro/2015, Faculdade de Direito da Universidade de Coimbra.

15. MARVILA LC, RAGGI DG. Projeto Horta para o desenvolvimento da Educação Ambiental na Educação Infantil. Revista Eletrônica Acervo Saúde, (25), e 634, 2019.

16. PENTEADO HD. Meio Ambiente e a formação de professores. São Paulo: Cortez, 1997.

17. RODRIGUES LHPF. A educação ambiental crítica e problematizadora - não é uma opção, é a única saída para dar eficácia ao dispositivo constitucional. In: Revista Digital Simonsen. Rio de Janeiro, n.2, Mai. 2015.

18. ROOS A, BECKER ELS. Educação ambiental e sustentabilidade. Revista Eletrônica em Gestão, Educação e Tecnologia Ambiental, REGET/ UFSM, Rio Grande do Sul, v.5, n.5, p. 857-866, 2012.

19. SOUSA BS, SOUZA EA. A importância da educação ambiental na proposta pedagógica da educação infantil: um estudo na Creche Palmeiras em Sinop. Revista Eventos Pedagógicos. 2014; 5(11): 64 - 73.

20. TOZONI-REIS MFC. Temas ambientais como temas geradores: contribuições para uma metodologia educativa ambiental crítica, transformadora e emancipatória. Educar, Curitiba n.27, p.93-110. 2006, Ed. UFPR.

21. TRISTÃO M. As dimensões e os desafios da Educação Ambiental na sociedade do conhecimento. In: RUSCHEINSKY, Aloísio (org.). Educação Ambiental: abordagens múltiplas. Porto Alegre: Artmed, 2002.

22. TRISTÃO MP. Tecendo os fios da educação ambiental: o subjetivo e o coletivo, o pensado e o vivido. Universidade Federal do Espírito Santo, 2005. 